\title{
O diálogo entre o moderno e o antimoderno no discurso da Ação Integralista Brasileira
}

\author{
The dialogue between the Modern and Anti-Modern \\ in Brazilian Integralist Action
}

Natalia dos Reis Cruz*

\begin{abstract}
Resumo: O artigo aborda a Ação Integralista Brasileira, apontando para a relação entre os elementos modernos e antimodernos da sua proposta de organização social. Através da análise dos discursos dos seus três principais líderes, Plínio Salgado, Miguel Reale e Gustavo Barroso, conclui-se que o integralismo foi um movimento social moderno, que pretendia eliminar as consequências negativas da modernidade, recuperando os elementos tradicionais, sendo o principal exemplo o espiritualismo cristão.
\end{abstract}

Palavras-chave: Integralismo, Modernidade, Tradição

Abstract: The paper broaches the Brazilian Integralist Action, pointing to the relationship between modern elements and anti-modern in its proposal for a social organization. By analyzing the speeches of its three main leaders, Plinio Salgado, Miguel Reale and Gustavo Barroso, we conclude that the integralism was a modern social movement, which sought to eliminate the negative consequences of modernity, recovering the traditional elements, being the prime example christian spiritualism.

Keywords: Integralism, Modernity, Tradition

Dir-se-ía que para ser inteiramente moderno é preciso ser antimoderno: desde os tempos de Marx a Dostoievski até o nosso próprio tempo, tem sido impossível agarrar e envolver as potencialidades do mundo moderno sem abominação e luta contra algumas das suas realidades mais palpáveis. (Berman, 2007:22)

\footnotetext{
* Professora Adjunto I de História, Departamento de Fundamentos das Ciências Sociais, Instituto de Ciências da Sociedade e Desenvolvimento Regional, Universidade Federal Fluminense. Doutora em História Social pela Universidade Federal Fluminense. E-mail: $<$ ndrc@globo.com>.
} 


\section{Introdução}

A Ação Integralista Brasileira (AIB), movimento político de caráter fascista, fundada em 1932, foi um dos principais atores sociais no contexto da modernidade brasileira nos anos 30. A sua relevância está no fato de ter sido o primeiro partido de massas do Brasil, com cerca de 500.000 adeptos, e de seu discurso e sua proposta de organização do Estado e da sociedade terem atingido simpatizantes em vários grupos sociais.

São muitos os estudos sobre a AIB, englobando os clássicos (como os trabalhos de Hélgio Trindade, Ricardo Benzaquen de Araújo, Marcos Chor Maio, René Gertz, entre outros) até os mais recentes, com vários novos pesquisadores debruçados sobre as principais questões que cercam o surgimento e a natureza do integralismo brasileiro, bem como as diversidades regionais e locais do fenômeno em questão.

Tendo me dedicado à análise da questão racial no pensamento integralista em trabalhos anteriores, novas questões vêm chamando a minha atenção, ao me deparar novamente com as fontes produzidas pelas principais lideranças da AIB. Uma delas diz respeito às relações entre o moderno e o antimoderno no discurso integralista, e é sobre esta temática que o presente texto pretende trazer algumas colaborações para um entendimento cada vez mais aprofundado do integralismo.

Considero a Ação Integralista Brasileira um movimento político moderno, que compartilha da utopia criativa e da ideia de progresso e construção do novo, que caracterizam a própria modernidade; mas, paradoxalmente, recupera alguns elementos antimodernos que servem como baliza na construção da nova sociedade proposta pelo movimento, e um dos principais elementos são os valores cristãos ou, mais precisamente, o primado dos valores religiosos e espirituais em detrimento da cultura racionalista moderna.

O integralismo pode ser considerado um dos movimentos políticos e sociais que, no esteio da modernidade, reage às consequências negativas da própria modernidade, defendendo propostas de organização social que visem estancar o processo moderno de fragmentação, insegurança e instabilidade. Para tanto, usa um discurso próximo ao elaborado por vários movimentos reacionários e antimodernos, com críticas à razão, ao materialismo, ao individualismo burguês e ao cosmopolitismo. No entanto, os elementos antimodernos e a própria crítica da modernidade são reelaborados e ganham um novo significado para dar vazão a uma proposta de sociedade em que a própria utopia moderna de ordem e 
controle seja recuperada, tornando-se realidade. Daí o integralismo cair como uma luva na mensagem da epígrafe que abre este texto.

Para analisar essa questão, utilizo o discurso das três principais lideranças do integralismo: Plínio Salgado (líder máximo integralista), Miguel Reale e Gustavo Barroso. Considero que, embora possam ser encontrados discursos heterogêneos entre os integralistas e até mesmo entre os três líderes citados, existem convergências básicas, que dão coerência ao discurso do movimento como um todo. Os três autores são essenciais para a compreensão da natureza do movimento, visto que eram representativos das principais tendências dentro do integralismo, e suas obras são tidas como discursos legítimos do ideário integralista da época.

\section{O Conceito de Modernidade e a Inserção do Discurso Integralista}

É importante conceituar a modernidade para se compreender como o integralismo se encaixa no ideal moderno e como também reage a ele. A modernidade coincide com a ascensão do capital e sua influência nas relações sociais e de produção, contribuindo para dissolver antigos laços e criar novos tipos de relações, mais impessoais. A consolidação do sistema capitalista de produção e sua expansão para diversas áreas do globo levaram a chamada modernidade para muitas outras regiões, além da Europa. No entanto, como o capital e o capitalismo foram as principais forças dinamizadoras do processo de modernização, as críticas que se fazem à modernidade acabam por se confundir com críticas ao capitalismo enquanto sistema, levando a uma preocupante desconsideração para com a relativa autonomia entre o projeto e a utopia modernas e o capitalismo em si. Dessa forma, muitos aspectos da utopia moderna que ainda deveriam ser considerados para a construção de uma realidade mais igualitária são praticamente que deslegitimados pelo processo de crítica ao capital e suas consequências.

Da utopia moderna de controle do homem sobre a natureza e sobre tudo que está fora dele próprio pouca coisa restou, já que essa promessa moderna não se realizou, nem mesmo com o auxílio da ciência. A modernidade em sua dimensão capitalista contrariou a própria utopia moderna de mais felicidade, de edificação de uma sociedade mais aberta às potencialidades de todos, da possibilidade de projetar novos mundos e prever e prevenir ameaças aos anseios humanos de uma vida melhor. A modernidade trazida pelo capital trouxe, ao contrário, insegurança, 
instabilidade, desigualdade, incertezas e, principalmente, descontrole. O homem, que almejava ser o sujeito de todo o processo, muitas vezes é o objeto de forças estranhas, as quais não consegue controlar, como o mercado, por exemplo.

Marx e Engels falam das transformações modernas e da dissolução de antigas crenças e formas de organização econômica, social e política, associando-as estreitamente com o capitalismo, enfatizando a capacidade de criação destrutiva da burguesia e apontando para suas mazelas e para a possibilidade de criação de uma nova sociedade, em que as consequências nefastas da modernização capitalista sejam eliminadas (Engels, Marx, 1998).

Anthony Giddens, por sua vez, considera que faz parte da gênese moderna, desde o seu início, o seu poder de trazer insegurança, instabilidade e incerteza, mas que nos períodos mais recentes esse processo vem se aprofundando cada vez mais. As mudanças da modernidade são rápidas e constantes, trazendo uma descontinuidade intrínseca em seu bojo, e a criação de novas instituições como o Estadonação, e novos processos sociais, como a mercantilização dos produtos e da força de trabalho (Giddens, 1991).

Já Zygmunt Baumann afirma que a modernidade caracteriza-se pela purificação e colocação das coisas em ordem, atividades conscientes e intencionais, que dão origem a uma nova ordem artificial. A estabilidade é o fim supremo da modernidade, pois as utopias modernas almejam um mundo perfeito, que permanecesse para sempre idêntico a si mesmo, em que nada estrague a harmonia, nada fique "fora do lugar", um mundo sem sujeira e estranhos. A modernidade criou então a ideia de ordem e de caos, sendo aquela relacionada com um projeto e uma ação (Baumann, 1998).

Comparando-se as interpretações de Giddens e Baumann, podemos dizer que aquele enfatiza os aspectos concretos da modernidade, as suas consequências, enquanto este aponta para a grande utopia moderna, embora sua interpretação possa ser criticada, por tornar o fascismo quase que um produto inevitável da modernidade.

Não podemos desconsiderar que o anseio de ordem e controle fazem parte da utopia moderna, mas a busca pela concretização desse ideal pode dar origem a vários tipos de sociedade, sendo a sociedade fascista apenas uma delas. A própria ideia de ordem e controle podem ter significados distintos. Não esqueçamos que Marx advogava um tipo de sociedade totalmente diferente, em que a ordem e o controle fossem exercidos conjuntamente pelos produtores associados, gerando 
uma organização social mais igualitária, e sua esperança dessa nova sociedade e a forma como a concebia também fazem parte da utopia moderna.

Assim sendo, acho apropriado falarmos de categorias abstratas, que podem se prestar a diferentes práticas políticas e sociais, de acordo com o projeto no qual estão inseridas. Podemos enumerar várias delas, além das categorias já citadas de ordem e controle: liberdade, igualdade, fraternidade (a famosa tríade da Revolução Francesa), por exemplo, inscrevem-se também nas utopias modernas, indicam a possibilidade de criação de uma nova sociedade, despida dos preconceitos e constrangimentos tradicionais, dando vazão à autonomia individual e ao sujeito. Muito embora tenham se prestado à edificação da sociedade burguesa e capitalista, foram e são recuperadas constantemente para projetos de organização social os mais variados, incluindo o comunismo e o próprio fascismo.

Os autores supracitados, em que pese as suas diferenças ideológicas e metodológicas, bem como suas conclusões distintas, abordam aspectos considerados essenciais para analisarmos a inserção do discurso integralista na questão da modernidade. Falam das mudanças que a sociedade moderna trouxe aos indivíduos, abordam categorias abstratas que fazem parte do discurso da modernidade, enfim, enfatizam a descontinuidade constante, a fluidez das relações sociais, a criação do novo e a utopia.

O integralismo não está fora dessas discussões, pelo contrário, participa delas, dialoga com todas as questões trazidas pela modernidade, apresenta um projeto político que procura solucionar muitos dos problemas da sociedade moderna, é prenhe da utopia moderna, muito embora a nova sociedade que propõe não abdique de elementos tradicionais, antimodernos ou arcaicos.

Para Ricardo Benzaquen de Araújo, o integralismo não pode ser vinculado à ideologia conservadora tradicional, já que em seu discurso está presente um "espírito revolucionário (Araújo, 1987:19-20). O autor refere-se à associação do integralismo com o totalitarismo, devido a uma concepção absolutizada da participação política das massas no processo de construção da nova sociedade e à equivalência entre igualdade e uniformidade no discurso integralista. $\mathrm{O}$ que nos interessa aqui é a ênfase no "espírito revolucionário", a ideia do novo, da criação de uma nova sociedade, que coloca o integralismo do lado da modernidade. Ao contrário do que Araújo fala, porém, não ocorre um corte absoluto com as tradições anteriores, e sim a permanência do ideal de uma sociedade 
estritamente hierarquizada e de elementos antimodernos (como a religião, por exemplo), baseado no modelo medieval de organização social.

A defesa de uma "nova sociedade" é baseada nos postulados fascistas, em que a questão social e a expropriação capitalista não são resolvidos por meio da luta de classes universal, mas pela colaboração de todas as classes dentro da nação (Sternhell, 1979). Tal colaboração exige a liquidação da sociedade liberal e do homem liberal, o "indivíduo". Este deve ser substituído pelo "novo homem", desprovido de interesses particulares, solidário ao próximo e identificado com a doutrina (Araújo, 1987:34).

O integralismo, assim como os fascismos de modo geral, fazem parte da modernidade, são movimentos modernos porque possuem uma utopia criativa e destrutiva ao mesmo tempo, característica da modernidade. No integralismo, a utopia criativa ou destruição criativa está presente em vários discursos das lideranças do movimento, mas estreitamente associado com um elemento absolutamente antimoderno: o espiritualismo cristão. Este é o motor da criação dessa nova sociedade e desse novo homem. Afinal, como construir uma nova sociedade sem reformar o homem, perguntavam-se os integralistas!

Toda a crítica integralista ao materialismo se fundamenta na defesa dos valores espiritualistas. Plínio Salgado concebia o materialismo e o espiritualismo como dois planos essenciais e antagônicos da existência humana, cuja presença teria sido constante em todos os tempos históricos. $\mathrm{O}$ triunfo do materialismo resulta na valorização do poder e do dinheiro entre os homens, assim como do individualismo e do egoísmo (Salgado, 1935:46).

Um paradoxo entre o moderno e o antimoderno aparece no discurso pliniano contra o materialismo e em defesa do espiritualismo. Plínio identificava o materialismo com leis naturais, que regem o comportamento do reino animal, vegetal, os fenômenos físicos e o comportamento humano. Agir instintivamente, sem consciência e sem controle, seria consequência da concepção materialista da vida, na qual o homem se deixa levar pelas leis naturais, sem nenhum tipo de autonomia ou atitude consciente. A existência humana passaria, assim, a ser regida pelos instintos, pelas "leis da selva", levando à competição desenfreada. Tais leis naturais possuiriam um caráter "cego" e "inconsciente", e assim também estaria o homem, ao agir por intermédio delas (Salgado, 1935:44).

Enquanto o moderno racionalismo iluminista prometia ao homem se desvencilhar das crenças religiosas, podendo tornar-se senhor de 
seu destino e livre para intervir na realidade e modificá-la - visto que a concepção teológica tradicional não deixava outro papel ao homem a não ser aceitar a realidade como era, vendo-a como fruto da "vontade divina" -, no discurso integralista, o racionalismo moderno contribuiria para fortalecer o caráter "cego" e "inconsciente" do homem, que não teria nenhum controle sobre a realidade, mas a ela se submetendo. Para o integralismo, são exatamente os valores espiritualistas cristãos que teriam o poder de despertar o homem dessa "inconsciência", tornando-o consciente e sujeito de sua história, e não dominado por "leis naturais" que não controla. Assim, é o elemento tradicional e antimoderno que teria a função, na percepção integralista, de realizar a promessa moderna de possibilitar ao homem o controle consciente de seu destino. Enquanto o elemento moderno (a razão materialista) não faria senão obstaculizar o potencial humano de realização.

Novamente recorremos a Plínio Salgado para demonstrar esse paradoxo descrito acima. Segundo ele, a interferência dos valores espirituais nas leis da matéria não é automática, porque a concepção espiritualista da vida não é algo natural e nem dirigida por leis inconscientes. Ela depende da vontade e da consciência humanas para se concretizar, sendo necessária, inclusive, a participação de todos na construção da nova sociedade, pois a união possibilitaria a intervenção e a modificação do curso "natural" das leis da matéria. O conceito de "revolução" aparece associado a essa ideia, sendo um movimento autêntico somente se for comandado por uma doutrina que possibilite aos militantes a mobilização em função dos princípios defendidos pela concepção espiritualista da existência (Salgado, 1935:44).

O modelo de sociedade que Plínio Salgado evoca é a civilização monoteísta medieval, em que haveria a dissolução das distinções e barreiras entre os homens, homogeneizando o seu comportamento com base na moral religiosa, cujo valor mais alto seria a busca da piedade e da existência fraternamente disciplinada. O livre-arbítrio, o relativismo e a experimentação teriam abalado o caráter absoluto e invariável do cristianismo medieval, gestando o mundo moderno (Salgado, 1935:85).

As categorias abstratas modernas aparecem claramente nos discursos do líder integralista. O que dizer da fraternidade, um dos três elementos elevados a valor supremo pela Revolução Francesa? Pois a realização concreta dessa categoria na sociedade só seria possível por intermédio do espiritualismo cristão. Plínio Salgado enfatizava que, além de afastar os homens de Deus, a razão moderna impede que eles se relacionem com 
o mundo do ponto de vista da totalidade, ou seja, preocupem-se com o destino de seus semelhantes. Isso decorreria da mentalidade analítica imposta pela ciência que, ao exigir que tudo seja testado e provado empiricamente, levaria à desagregação do todo em partes separadas e específicas. Em consequência, o próprio homem começa a se ver como parte, como indivíduo egoísta e solitário, perdendo a solidariedade fraterna estimulada pelo espiritualismo (Salgado, 1935:85-90).

A relação paradoxal entre o elemento moderno e o antimoderno é uma constante nos discursos integralistas. A modernidade é descrita como o domínio da concepção materialista e ateísta, demonstrada pelo iluminismo e pelas revoluções burguesas. Inclusive, o Estado liberal-democrático representaria o ateísmo e o materialismo, visto que não intervém na realidade social e econômica, deixando as "leis naturais" da competição e da desagregação agirem livremente. Os integralistas percebiam claramente que as ideias de homem cívico e de soberania nacional que baseavam este Estado não se concretizavam, pois a sociedade liberal é dividida em indivíduos e grupos antagônicos. Assim, o Estado gerado pela modernidade não possibilita o controle dos indivíduos e grupos sobre seus destinos, pois favorece a fragmentação da sociedade, tornando-os somente sujeitos de conflitos sociais. O Estado liberal representa apenas interesses inexistentes (os valores universais e abstratos, vinculados ao homem cívico e artificial), por isso não teria eficácia e nem legitimidade (Salgado, 1933:48).

As leis da matéria teriam seu curso de ação livre pelo imobilismo do liberalismo político e pelo afastamento do espiritualismo por parte da ciência. Assim sendo, a única forma do homem obter o controle sobre sua existência seria recuperar os valores espirituais cristãos, e organizar a sociedade de acordo com eles. Os integralistas faziam uma crítica da sociedade moderna, atentando para os problemas gerados pelo capitalismo, como a exploração e a miséria das massas operárias e a competição desenfreada entre os capitais, mas reduzem tudo à questão do materialismo, desprezando a luta de classes e a possibilidade de superação do sistema capitalista e da propriedade privada burguesa. Pois, na humanidade ateísta, a valorização do conflito e da desordem viria acompanhada do desaparecimento dos padrões morais. A solução dos problemas sociais viria com a adoção dos valores cristãos de solidariedade, piedade e amor ao próximo e a edificação de um Estado forte que agregasse todos os grupos sociais harmonicamente.

Logo, a ideia de revolução, no integralismo, seria também restauração. Segundo Hannah Arendt, a palavra revolução não era 
originariamente sinônimo de novidade, mas designava repetição ou movimento cíclico (Arendt, 1971:41). Para os integralistas, revolução significaria o retorno dos valores espirituais da Idade Média, e até mesmo de algumas concepções organizativas da sociedade medieval, como o corporativismo, com o objetivo de ordenar a nova sociedade que se queria construir.

Mas é importante atentar para o fato de que os integralistas não defendiam o retorno da antiga forma de sociedade. $\mathrm{O}$ que eles almejavam era uma nova sociedade que combinasse padrões modernos (como o industrialismo e o desenvolvimento econômico capitalista) com elementos antimodernos considerados úteis para organizar tal sociedade. A restauração que defendiam não era de um tipo de sociedade anterior, mas dos princípios que a regiam. Por isso, eram ao mesmo tempo modernos e antimodernos.

Um outro elemento constituinte da modernidade fazia parte do integralismo: o nacionalismo. A ideia de nação só pôde se desenvolver historicamente com a dissolução das hierarquias tradicional e rigidamente consolidadas, que separavam os homens em categorias sociais distintas. $\mathrm{O}$ advento dos valores modernos de igualdade e liberdade contribuíram para o reconhecimento do outro como um companheiro nas agruras da vida, e compartilhando determinados interesses e identidades comuns, o que possibilitou a criação do mito do pertencimento a uma ideia de comunidade ampla gerida por um Estado com jurisprudência sobre um dado território.

Ernest Gellner vê a nação como um artefato político levado a cabo pelo Estado nacional, em um contexto histórico marcado pela industrialização da sociedade. A nação seria uma comunidade, em parte, produzida e sustentada pelos Estados nacionais, por meio da padronização cultural e lingüística de seus membros, fazendo com que grupos estrangeiros, cultural e etnicamente distintos, sejam marginalizados, constituindo-se em uma "falha de comunicação", que pode ser resolvida pela assimilação ao grupo dominante (Gellner, 1993:103).

O Estado moderno é aberto a todos, pois todos são considerados iguais. Por isso, ele se designa como Estado-nação, pois representa toda a nação. É claro que estou abstraindo a realidade concreta dos Estados modernos de tipo burguês que, na prática, legitimam e consolidam os interesses da classe burguesa como um todo, assegurando a acumulação do capital. O que interessa aqui é como os Estados modernos se autodefinem, pois é inconcebível que eles assumam abertamente que contêm um caráter de classe. Assim, a ideia de interesse geral é uma presença 
constante nos discursos estatais. A ideia integralista de Estado não foge à regra. Miguel Reale foi quem melhor definiu o conceito de Estado no integralismo:

O Estado é a Nação organizada. É a organização hierárquica e solidária dos indivíduos e dos grupos que congregam esforços com o fim de alcançar um máximo de felicidade pessoal e geral. O Estado não se confunde com uma classe, nem com um grupo, só pode exprimir a totalidade da Nação. Por esse motivo, o Estado é soberano, está acima das classes, sendo superior a todas elas pela força de que deve dispor e pelos fins que deve realizar (Reale, 1983:16).

Nota-se, no trecho supracitado, a noção de hierarquia e solidariedade, que se mesclam nos discursos integralistas para gerar a ideia de harmonia e coesão social. Aqui subentende-se a negação do individualismo liberal e conflituoso, com a recuperação de um valor tradicional e até mesmo antimoderno, como a hierarquia das posições. Porém, a negação do individualismo e a defesa da hierarquia não significam uma negação da ideia moderna de indivíduo. Pelo contrário, as diferenciações são relacionadas às capacidades e vocações individuais. Isso aparece mais claramente na concepção econômica de Nação, segundo o próprio Reale (1983:15).

É claro que a definição de Reale acima exposta faz abstração total da expropriação que gerou o capitalista, e da desigualdade de condições gerada pelo sistema, relacionando a posição de trabalhador e de capitalista a simples resultado de vocações e capacidades individuais. Mas para o que estamos discutindo, o que importa é que a noção moderna de indivíduo está presente no discurso de Reale, e ela aparece combinada com a noção de hierarquia (mais apropriada a sociedades tradicionais). $\mathrm{O}$ moderno e o antimoderno se combinam novamente.

A ideia do corporativismo, também baseada numa concepção organizativa medieval (tais como as corporações de ofício), é combinada, por sua vez, com a ideia de democracia moderna, em que todos devem ter o direito e a possibilidade de intervir nos assuntos públicos e na gerência do Estado. Segundo Reale, a organização corporativa seria a única capaz de possibilitar a participação de todos no Estado, pois é do seio das profissões organizadas que deveriam sair os representantes da Nação. Todos os trabalhadores (no caso, usam a categoria trabalhador para todos os grupos, inclusive os capitalistas) deveriam se unir em associações para se fazerem representar no Estado, com paridade de 
direitos e deveres e com espírito de colaboração (Reale, 1983:16-17 e 19).

O espiritualismo cristão seria o cimento da democracia orgânica defendida pelo integralismo. Assim, é o elemento antimoderno de fundo religioso que garantiria a possibilidade de existência da democracia moderna na futura sociedade integralista. Os valores espirituais baseiam toda a crítica que os integralistas fazem ao conflito social, e são usados na defesa da harmonia entre capital e trabalho e do uso social da propriedade privada. Ou seja, não negam o capital, apenas querem discipliná-lo em prol do bem comum, cabendo ao Estado respeitar a iniciativa privada e o campo da atividade individual, mas também assegurar que o proprietário não ameace os direitos dos não-proprietários (Reale, 1983:24).

O conceito moderno de liberdade também está presente no ideário integralista, a despeito de ser um movimento de caráter autoritário. Paradoxalmente, defendem a liberdade efetiva para todos, o que seria garantido através do primado do espiritualismo (desenvolvendo-se as categorias de liberdade positiva e liberdade negativa), e a crítica que fazem ao liberalismo é por este garantir somente a liberdade negativa, gerando a falta de liberdade de fato para os indivíduos (Reale, 1983:29 e 80).

O conceito de "liberdade negativa" designa, então, uma liberdade permissiva, cuja principal consequência seria o não respeito pelos direitos do outro, resultando na "anarquia social". A liberdade negativa geraria indivíduos agressivos que não se importam com o bem-estar de seu semelhante, capazes de passar por cima dos direitos alheios, a fim de alcançarem seus objetivos e interesses. Configurar-se-ia, portanto, uma situação social de conflito e desagregação, que ameaça a integridade da vida nacional (Salgado, 1959:23-24).

Logo, os integralistas, em sua luta política contra a sociedade liberal, opõem um projeto de sociedade com base na chamada "liberdade positiva". O conceito de liberdade pode adquirir variados significados, de acordo com a ideologia política que o utiliza. No caso dos integralistas, a ideia de liberdade não está descolada de sua visão de sociedade e do seu projeto político de nação. O integralismo lutava por uma sociedade desprovida de conflitos, harmônica, integrada, indivisível e una, onde a coletividade - a nação -, representando o bem comum, sobrepusesse qualquer interesse individual ou de grupos.

Dentro desta visão de sociedade, a liberdade deveria servir para preservar a harmonia e o equilíbrio social e nacional, opondose a quaisquer movimentos de separação e desintegração advindos 
da supremacia das partes sobre o conjunto da vida nacional. Daí, o integralismo desenvolveu as categorias de liberdade positiva e liberdade negativa, procurando mostrar que não se opunha à liberdade em si, mas a determinadas formas de liberdade, consideradas ameaçadoras para a coletividade como um todo.

Miguel Reale resume a ideia de liberdade na concepção integralista:

é consciência da própria dignidade de homem, compreensão da missão que cabe a cada qual como indivíduo e como pessoa, harmonia permanente entre o conjunto dos direitos e a correspondente soma dos deveres, sem os quais os primeiros não existem, nem nunca existirão (Reale, 1983:221).

Para os integralistas, a liberdade positiva remete à ideia de que os direitos individuais devem ser preservados, porém, sem prejuízo para a coletividade. Já a liberdade negativa seria derivada do individualismo excessivo, capaz de dissolver os vínculos afetivos e sociais, originando a anarquia e a desordem e prejudicando a nação.

Reale chama de harmonia social o estado em que a liberdade fosse socializada para todos e, para isso, seria preciso impor limites às ações individuais. E conclui dizendo que "o nosso conceito de liberdade é complexo e realista, visando a defesa dos direitos naturais do indivíduo e da pessoa, sem sacrificar o supremo direito do Estado que é o de coordenar e dirigir, e sem ofender os valores morais, para o bem particular de cada qual e o bem comum da Nação" (Reale, 1983:85).

Já Gustavo Barroso enfatiza a supremacia dos interesses nacionais sobre os individuais como forma de se preservar a própria integridade dos indivíduos, "de sorte que o indivíduo submetendo-se aos supremos interesses nacionais, não faz mais do que defender a sua própria intangibilidade" (Barroso, 1933:101).

A interseção entre o moderno e o antimoderno reside na associação da moderna defesa do indivíduo e da noção integralista de liberdade com uma concepção moral e ética das relações interpessoais, baseada na visão espiritualista do mundo: "Onde não existe consciência moral não pode existir compreensão de liberdade. Eis porque o Integralismo se declara pelo espiritualismo, sem preferência de cultos e de crenças, mas exigindo de todos os seus adeptos a nota espiritualista" (Reale, 1983:221).

Para os integralistas, a liberdade positiva anda de mãos dadas com a solidariedade e com o espírito cristão, visto que o conjunto da 
vida social não é esquecido. Isto é, defende-se os direitos individuais, mas não em detrimento do outro; reconhece-se que o ser humano, enquanto ser único, possui direito à liberdade, mas que, ao enxergar o outro como seu semelhante, percebe que sua liberdade não é ilimitada, visto que a liberdade do outro também deve ser preservada. É uma liberdade integradora, cujo sentimento de identidade com o outro permite a manutenção da harmonia social. Assim, dizia Miguel Reale: "Reconhecemos os valores particulares e exclusivos dos indivíduos, mas não fazemos do indivíduo um absoluto" (Reale, 1983:65-66).

$\mathrm{O}$ projeto da modernidade era baseado na ideia de progresso e conquista da felicidade, daí a visão extremamente otimista que acompanhou o início da era moderna, tendo a ciência como um dos pilares desse otimismo. O integralismo não abdica da ideia de progresso e nem da crença num futuro melhor e mais feliz, pois está eivado do espírito da modernidade. Mas torna essas promessas modernas totalmente dependentes do predomínio de uma concepção de ordem e moralidade. A moral adviria do respeito aos valores espirituais máximos, calcados na cultura cristã, e a concepção de política está ligada ao objetivo de construção da nova sociedade e do homem, sendo vista como "uma ciência de alto valor moral que ensina a dirigir sábia e honestamente os homens, organizando-os com disciplina e justiça em corpos coletivos, orientando-os para o progresso dentro da ordem e da moralidade, procurando assim, torná-los tão felizes quanto o permitam as possibilidades de seu destino à face da terra" (Barroso, 1933:15).

Procuramos até aqui demonstrar que o projeto político da Ação Integralista Brasileira está completamente inserido em uma perspectiva moderna, na medida em que reitera uma dimensão utópica e criativa e salvaguarda, no discurso de suas principais lideranças, o cumprimento das promessas da modernidade, atentando para a necessidade do sujeito conscientemente controlar o seu destino e atuar na construção de uma nova sociedade. O paradoxo está no fato de subordinar todo o lado moderno de sua ideologia a uma concepção tradicional e antimoderna da vida, colocando a dimensão espiritualista e cristã como a grande diretora de todo o processo. A própria ideia de "homem integral" deixa isso claro. Segundo Barroso, a "tríplice natureza do Homem" seria instintiva ou material, anímica ou racional e espiritual ou superior (Barroso, 1933:23).

Mas essa síntese social seria o homem dotado de vontade, mas norteado por um princípio Superior de bondade, uma inspiração Superior de verdade e uma exaltação Superior de fé ou sabedoria, tornando 
a marcha totalmente vitoriosa. Logo, o homem deveria "recobrar" a sua consciência - despertando para o espiritualismo e livrandose da "cegueira" e da "inconsciência" trazidas pelo materialismo -, tornando-se o sujeito autônomo de seu destino; porém, paradoxalmente, a sua autonomia não é absoluta, pois deve se subordinar aos desígnios superiores de uma suposta divindade. Os integralistas legitmam todo um projeto político e social na antiga ideia de "vontade divina", já que são os valores cristãos que devem ser os grandes inspiradores da ação política, social e econômica do homem em sociedade.

Este aspecto antimoderno do integralismo convive o tempo inteiro com o lado moderno do seu discurso. Enquanto as categorias modernas de liberdade, fraternidade e até mesmo a ideia de democracia (embora numa concepção orgânica) estão presentes na fala dos líderes do movimento, a categoria da igualdade praticamente não aparece. Gustavo Barroso, pelo contrário, nega a noção moderna de igualdade, o que também não é prerrogativa apenas dos fascismos em geral, mas do próprio racismo. Barroso afirmava que os homens nascem fisicamente desiguais, gerando a desigualdade social e política, e a hierarquia seria, por conseguinte, um fenômeno natural (Barroso, 1933:33).

$\mathrm{Na}$ esteira do ataque à igualdade, Barroso estende sua crítica também à noção de soberania popular e à "destruição" das instituições seculares pelo racionalismo (leia-se as religiões), apresentando-se como defensor dos poderes políticos tradicionais baseados numa suposta divindade dos mesmos, cabendo ao povo simplesmente subordinar-se a essa vontade espiritual maior (Barroso, 1933:40). Uma perspectiva totalmente tradicional de poder político, que vai na contramão da ideia moderna dos indivíduos como sujeitos da criação do Estado e da sociedade política e reitera a noção de hierarquia.

A negação explícita da igualdade aparece com mais clareza no discurso de Barroso, não sendo tão veemente nas obras de Plínio Salgado e Miguel Reale. Nestes, embora o termo igualdade não seja uma categoria presente em seus pensamentos, a noção igualitária parece, às vezes, ficar subentendida na ideia de representação de todos no Estado via categorias profissionais (igualdade política) ou até mesmo na defesa de uma certa uniformidade ou homogeneidade étnico-racial e cultural.

O projeto integralista de nação tinha como objetivo a construção e formação de uma homogeneidade racial e étnica da população, através do caldeamento racial e cultural, resultando no almejado predomínio da raça e cultura brancas. Este projeto é justificado por sua pretensa 
autenticidade, supondo-se que a miscigenação está ligada às tradições históricas, culturais e religiosas da nação, ou seja, estaria atrelada à "alma" e à "subjetividade" nacionais, moldadas desde o processo histórico da colonização (Cruz, 2004:256).

Nesse sentido, igualdade se confundiria com uniformidade, resultando na imagem de uma sociedade desprovida de conflitos e diferenças, composta por cidadãos homogêneos e ativos, segundo a perspectiva pliniana (Araújo, 1987:21). Em Reale, por sua vez, a noção implícita de igualdade está associada com a noção de liberdade positiva, pois, ao atacar o liberalismo, um dos argumentos, conforme já citado, é que este só garante a liberdade aos mais fortes, ao passo que o integralismo pretenderia garanti-la a todos igualmente, sendo imprescindível, para isso, que o espiritualismo cristão predominasse nas relações sociais.

Mas é bom ficar claro que a concepção integralista de igualdade, quando aparece implícita nos discursos de algumas lideranças, em nada se relaciona com uma igualdade social e econômica, pelo contrário. A propriedade privada é considerada legítima, devendo-se apenas ser administrada pelos limites impostos pelo bem comum, bem como as diversas classes sociais deveriam continuar existindo numa futura sociedade integralista, pois o que o integralismo repele não são as classes em si, mas a luta entre elas, que devem se harmonizar no espírito cristão de colaboração.

\section{Conclusão}

O integralismo era caracterizado por um discurso bastante dúbio, mesclando elementos modernos e antimodernos em sua doutrina e proposta de organização social e política. Podemos interpretar esta dubiedade fazendo referência à própria sociedade brasileira do período, ainda em transição para a modernidade, com a forte presença de resquícios da velha ordem e das elites tradicionais.

A organização da AIB foi levada a cabo por uma parte dos setores médios identificados com o ideal autoritário e conservador de Estado. A elite pensante do movimento era formada por advogados (Miguel Reale e Gustavo Barroso), jornalistas e/ou escritores (Plínio Salgado), economistas (Raimundo Padilha), professores, etc. Constituíam um grupo social que buscava garantir o espaço das camadas médias na sociedade em vias de industrialização, interessado então em controlar o processo de transformação social em curso, disciplinando o grande capital e o 
proletariado. Daí advinham, em grande parte, os discursos integralistas contra o capital financeiro internacional, a urbanização acelerada, o cosmopolitismo e o comunismo. A fórmula política encontrada por esses setores foi a constituição de um Estado corporativista autoritário, acompanhado de toda uma doutrina nacionalista, que pregava a exclusão e a intolerância, em nome da identidade nacional e da homogeneização étnico-racial e cultural do povo brasileiro, tendo como substrato os valores espiritualistas cristãos.

Vários autores analisaram a situação das camadas médias na sociedade brasileira em transição, indo desde a afirmação de que o seu inconformismo ou radicalismo não conduzia a um projeto político autônomo, pois eram dependentes, a nível sócio-econômico, da estrutura predominante (Fausto, 1986:26), até a ênfase na dubiedade do comportamento político do grupo que, apesar de apresentar críticas efetivas ao regime político, defendia propostas estritamente conservadoras e ou ligadas ao campo liberal, não contemplando a realização plena da democracia (Mendonça, 1990:234).

No meu entender, a presença de fatores modernos e antimodernos no discurso dos integralistas também pode ser associada à própria modernidade incompleta da sociedade brasileira do período, aliado ao fato de haver uma profunda influência do processo de renovação espiritual que caracterizou o período em questão. Segundo Trindade, tal processo se manifestava sob a influência da renovação católica na França e se iniciou no fim do século XIX, com o objetivo de restaurar os valores espirituais na poesia, na prosa e na filosofia, contra o espírito naturalista e positivista. Este movimento espiritualista foi marcado pelo antimodernismo, pelo anti-burguesismo e pela nostalgia da Idade Média. No início do século, ele começa sob a influência do catolicismo reacionário e de correntes contra-revolucionárias da segunda metade do século XIX, e torna-se mais liberal entre as duas guerras, sob a inspiração do neotomismo. Tal movimento iniciou-se com o advento da República, após a separação entre a Igreja e o Estado, em 1890 (Trindade, 1979:98).

A AIB era portadora de um profundo conservadorismo, que mesclava o reacionarismo (manifestado nas críticas contundentes às consequências da modernidade associadas à construção mítica de um passado supostamente espiritualista) com o moderno, cujo objetivo seria a integração à ordem social presente, evitando-se os conflitos gerados dentro dela. Seu conservadorismo pode, portanto, ser definido da seguinte forma: 
um corpo teórico articulado, musculoso e seminal, capaz de combinar apego à técnica e sonhos românticos sobre uma Idade Média que nunca existiu; racionalidade tecnológica e os mais profundos preconceitos sociais ou raciais, desenhando contradições que marcaram o século XX e ameaçam invadir o século XXI (Silva, 2000:21).

Eis o que designava o integralismo: um movimento que combinava o desejo de restaurar um passado idílico, quando os grupos sociais interagiam em perfeita harmonia, com propostas ligadas ao pensamento conservador moderno, como a defesa de um Estado forte, capaz de harmonizar corporativamente os corpos sociais.

Não se desejava lutar contra o processo de industrialização, mas produzir um arranjo institucional por meio de um projeto de nação que englobasse os interesses industriais e médios e controlasse o movimento popular. Para isso, era necessário que o sistema político liberal oligárquico fosse substituído por uma outra forma de organização do Estado, que pudesse garantir a harmonia social.

O integralismo pertence à modernidade, pois seu discurso é eivado das mais famosas categorias modernas: liberdade, fraternidade, democracia, indivíduo. Os integralistas não negam nenhuma delas, apenas dão a elas um lugar e uma interpretação bem peculiares e funcionais ao seu projeto de sociedade.

$\mathrm{Na}$ ideologia integralista, o moderno está presente no projeto de engenharia social que visava colocar de cabeça para baixo a realidade existente, e edificar uma nova. Algumas ações eram consideradas essenciais: seleção das raças aptas a participar do caldeamento racial e da miscigenação como forma de eliminar as raças "inferiores" e sua "influência negativa" sobre o caráter da nação que se quer construir; organização de um Estado forte e de uma organização representativa de base corporativa; eliminação dos conflitos de classe.

Mas tal qual a construção de uma nova casa, a "nova sociedade" precisava de um cimento que mantivesse em harmonia todos os seus elementos; o cimento eram os valores espiritualistas cristãos, era o mito da recuperação de um passado espiritualista e harmônico; a ressurreição dos elementos cristãos é que garantiria que a "nova sociedade" fosse o contrário da sociedade trazida pela modernidade: coesa, harmônica e segura. Era necessário, também, um "novo homem", que agisse em conformidade com os preceitos cristãos e reconhecesse que, para além dele, existe um Ser Superior, cujos desígnios deveriam ser respeitados para que se construísse uma sociedade à imagem e semelhança de uma suposta Ordem Divina. 
$\mathrm{O}$ aspecto tradicional é, assim, representado pela cultura dos valores religiosos - o cristianismo -, que pauta todo o discurso referente às relações sociais entre as classes e entre a sociedade e o Estado. A modernidade tem como uma de suas características a libertação do homem frente a uma suposta ordenação divina do mundo e da sociedade. O homem passa a ser o senhor de seu destino e de sua história. Os integralistas, ao contrário, enfatizavam que a ação humana deve ser limitada pelos valores cristãos, construindo, portanto, um discurso tradicional.

Mas como quase tudo era dúbio no integralismo, o espiritualismo pode ser interpretado tanto como veículo do arcaico e antimoderno quanto como instrumento de "libertação" do homem frente ao "inconsciente" e às leis naturais, recuperando a possibilidade de controle do sujeito sobre o processo social, não através da razão, mas por meio do "despertar das consciências", nos dizeres integralistas. Nesse caso, o espiritualismo seria também a via para a realização da utopia moderna, que a própria modernidade não conseguiu atingir.

Eliminar as consequências negativas da modernidade e concretizar a utopia moderna, qual seja, a felicidade, a segurança, o controle e a realização "efetiva" da liberdade, da fraternidade e, em alguns casos, da igualdade, estavam nos planos dos integralistas. O elemento antimoderno (os valores cristãos) seria essencial para a conquista dos anseios da modernidade.

A preocupação moderna com a ordem e a estabilidade está no cerne da condenação integralista ao individualismo excessivo. É uma tônica comum a todos os fascismos (sendo o integralismo a variante nacional brasileira), representando uma reação à insegurança e à instabilidade trazidas pela vida moderna. O novo homem e a nova sociedade fascistas propõem recuperar a estabilidade e fornecer um lugar fixo para o sujeito na sociedade.

Os fascismos são, portanto, um dos produtos da modernidade, mas não um produto inevitável, pois a modernidade possui dimensões bastante positivas e que devem ser resgatadas como forma de se combater, inclusive, as propostas e práticas autoritárias, excludentes e, por que não dizer, fascistas das nossas sociedades atuais.

\section{Referência}

ARAÚJO, Ricardo B. Totalitarismo e Revolução. O Integralismo de Plínio Salgado. Rio de Janeiro: Zahar, 1987. 
ARENDT, Hannah. Sobre a Revolução. Lisboa: Moraes Editores, 1971.

BARROSO, Gustavo. O Integralismo em Marcha. Rio de Janeiro: Schmidt, 1933.

BAUMANN, Z. O mal-estar da pós-modernidade. Rio de Janeiro: Zahar, 1998.

BERMAN, Marshall. Tudo que é sólido desmancha no ar. A aventura da modernidade. São Paulo: Cia. Das Letras, 2007.

CRUZ, Natalia R. O Integralismo e a Questão Racial. A Intolerância como Princípio. 2004, 281 p, Niterói, Tese de Doutorado, Programa de Pós-Graduação em História Social, Universidade Federal Fluminense.

ENGELS, F. \& MARX, Karl. O Manifesto do Partido Comunista. Petrópolis: Vozes, 1998.

FAUSTO, Boris. A Revolução de 30. Historiografia e História. SP: Brasiliense, 1986.

GELLNER, E. Nações e Nacionalismo. Lisboa: Ed. Gradiva, 1993.

GIDDENS, A. As Consequências da Modernidade. São Paulo: Unesp, 1991.

KOLAKOWISKI, Leszek. L'Espirit Revolutionaire. Bruxelas: Editions Complexe, 1978.

MENDONÇA, Sonia R. Estado e Sociedade: A Consolidação da República Oligárquica. In: LINHARES, Maria Yedda (org.). História Geral do Brasil. Rio de Janeiro: Campus, 1990, p. 316-326.

REALE, Miguel. Obras Políticas. Brasília: Editora da UNB, 1983.

SALGADO, Plínio. O Que é o Integralismo. Rio de Janeiro: Schmidt, 1933.

SALGADO, Plínio. Palestras com o Povo. Rio de Janeiro: Livraria Clássica Brasileira, 1959.

SALGADO, Plínio. Psicologia da Revolução. Rio de Janeiro: José Olympio, 1935.

SILVA, Francisco C. T. Introdução. SILVA, Francisco C. T., MEDEIROS, Sabrina E. \& VIANNA, Alexander M. (orgs.). Dicionário Crítico do Pensamento da Direita. Ideias, Instituições e Personagens. Rio de Janeiro: FAPERJ/Mauad, 2000, p. 11-21. 